\title{
EFFECTS OF ETHYL METHANESULFONATE ON MORPHOLOGICAL AND PHYSIOLOGICAL TRAITS OF PLANTS REGENERATED FROM STEVIA (STEVIA REBAUDIANA BERTONI) CALLI
}

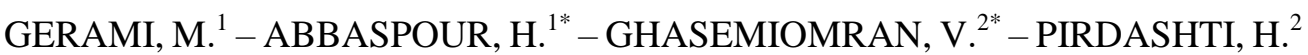 \\ ${ }^{1}$ Department of Biology, Damghan Branch, Islamic Azad University, Damghan, Iran \\ (MahyarGerami: +98-11-44221387,e-mail:mahyar.gerami@yahoo.com;Dr.Hossein \\ Abbaspour: +98-232-5235016,e-mail: Abbaspour75@yahoo.com) \\ ${ }^{2}$ Department of Agronomy \& Plant Breeding, Genetics and Agricultural Biotechnology Institute \\ of Tabarestan, Sari Agricultural Sciences and Natural Resources University, Sari, Iran \\ (Dr. Valiollah Ghasemiomran: +98-11-33687744, e-mail: Ghasemiomran@yahoo.com; \\ Dr.Hemmatollah Pirdashti:+98-11-33687744,e-mail:Pirdasht@yahoo.com) \\ *Corresponding authors \\ e-mail:Abbaspour75@yahoo.com, Ghasemiomran@yahoo.com
}

(Received $8^{\text {th }}$ Nov 2016; accepted $17^{\text {th }}$ Jan 2017)

\begin{abstract}
Calli induced from leaf explants cultured on medium containing $0.1 \mathrm{mg} / \mathrm{L}$ thidiazuron (TDZ) were exposed to various concentrations of EMS $(0.1,0.2$, and $0.5 \%)$ at different time courses $(30,60$, and 120 minutes). The effects of the various concentrations of EMS and different exposure times and the interactions of these factors on the traits of regenerated calli were significant. The number of produced shoots declined with increases in EMS concentrations and in exposure durations. EMS also had significant effects on the morphological and physiological traits of the regenerated plants. Among the 12 studied traits, the $\mathrm{M}_{10}, \mathrm{M}_{11}$, and $\mathrm{M}_{6}$ mutant lines exhibited the highest variation in terms of morphological and physiological characteristics compared to the control. Among the studied mutants, $\mathbf{M}_{10}$ had the maximum shoot dry weight, root fresh weight, and chlorophyll a and carotenoid contents up to 102, 30, 358 , and $658 \%$ higher, respectively compared to those of the control. These mutant lines can be further used for improvement of physiological characteristics as well as for higher quantities and quality of terpene glycosides, such as rebaudioside-A, which does not have a bitter aftertaste.
\end{abstract}

Keywords: EMS, thidiazuron, mutant, in vitro, cullus

\section{Introduction}

Medicinal plants are among the most economically important crops that are used in raw or processed forms. The ever-increasing global trend towards the use of medicinal plants more clearly indicates the importance of growing and producing them (Triphati, 2003). Among the medicinal plants, stevia (Stevia rebaudiana Berton.) is considered both for medicinal and economical reasons. It is a short- day, perennial, and selfincompatible plant in the Asteraceae family native to the forests of Paraguay, Mexico, and Brazil, and grows in subtropical and semi-humid regions (Mondaca et al., 2012). The seeds germinate with difficulty and many of them are often sterile and unfilled grain and cannot be sown. Therefore, tissue culture is most often used for propagating stevia. This plant has terpene glycosides in its leaf tissues that have the properties of sweeteners, with the two main glycosides (stevioside and rebaudioside A) 250-300 and 350-450 times sweeter than sucrose, respectively (Taware et al., 2010).

Tissue culture has many applications for medicinal plants most importantly in rapid mass propagation of medicinal plants with uniform genetic and qualitative features, in 
preservation of endangered plant species through preserving them in the frozen state, and in production of secondary metabolites under in vitro conditions (Triphati 2003; Mulabaghal and Tsay, 2004).

Mutation is considered as a tool to study molecular nature and functions of genes. Under in vitro conditions, mutations prepare the ground for breeding plants by expanding their range of genetic diversity (Adamu and Aliyu, 2007). Use of mutagens is a rapid and new method employed for improving qualitative and quantitative traits in many plants. Mutagens can influence cytological, biochemical, physiological, and morphological properties of plant tissues and cells. Success in any mutagenesis program under in vitro condition depends on developing repeatable procedures for regeneration of plants. Under these conditions, mutagenic treatments and efficient screening of mutated populations are optimized to achieve desirable changes (Jain, 2006). Various studies have been carried out on using mutagens to improve physiological and biochemical properties of stevia. Khalil et al (2014) studied the effects of gamma rays on steviol glycosides in stevia plants. Calli of stevia were exposed to 5, 10, and 25 Gy gamma radiations to create genetic diversity and somaclonal variations. In another study, Abd El. Hamid et al. (2014) studied the effects of 750,1500 , and 2250 Gy gamma radiation on stevia calli under salt stress conditions, and reported that the maximum and minimum callus regeneration of 100 and 35 percent belonged to the treatments with 750 and 2250 Gy gamma radiation, respectively. Moreover, a study was conducted using 750, 1500, and 2250 Gy gamma radiation to induce genetic changes in order to increase stevioside content in stevia and improve its resistance to salinity (Ali et al., 2015)

Ethyl methylsulfonate (EMS) is used more commonly as a chemical mutagen on plants because of its high ability to induce mutations and since it is a simple compound. EMS alkylates induce point mutations. This mutagen attaches its alkyl groups to the oxygen bonded to guanine through hydrogen bonds and produces 0-6 alkylguanine that pairs with thymine instead of cytosine and replaces A/T by G/C. EMS influences a very short segment of chromosome that carries one or several genes, and can affect the cytological, genetic, physiological, and morphological traits of plant tissues and cells (Waugh et al., 2006). Studies have been carried out on the effects of this mutagen on various plants including those conducted by Sengutpa et al. (2005) and Saba and Mirza (2002) on sesame and tomato, respectively.

Because no research had been conducted to elucidate the role of EMS in creating and improving the diversity in stevia, the primary goal of this study was to produce new mutant lines of this plant using EMS. The resulted mutant plantlets were further analyzed in terms of morphological and physiological alterations.

\section{Materials and methods}

\section{The first experiment: induction of mutation under in vitro conditions}

Nodal segments from 1-year old stevia plants were first excised for explant preparation. After being washed under running water for half an hour, the explants (nodal segments) were sterilized with $70 \%$ alcohol for 30 seconds and then rinsed with sterile distilled water. Following that, they were disinfected for 20 minutes using $2 \%$ (v/v) sodium hypochlorite with one drop of Tween 20 and were finally rinsed with sterile distilled water three times. The sterilized explants then were cultured in hormone-free MS basal culture medium containing 3\% sucrose and $0.8 \%$ agar at $\mathrm{pH}$ of 
5.8 , and the culture containers were kept at $25^{\circ} \mathrm{C}$ under a $16 \mathrm{~h}: 8 \mathrm{~h}$ light-dark photoperiod. Regenerated plants were used as the source for preparing explants to be used in the experiments.

\section{Callus induction}

Leaf explants from 1-month old in vitro grown seedlings were transferred to MS medium containing $0.1 \mathrm{mg} / \mathrm{l} \mathrm{TDZ}$. Subculture of explants in similar media was carried out once every three weeks. Calli were formed after six weeks and were cut into smaller $5 \mathrm{~mm}^{2}$ segments to be used for applying the EMS treatment (Figure 1).

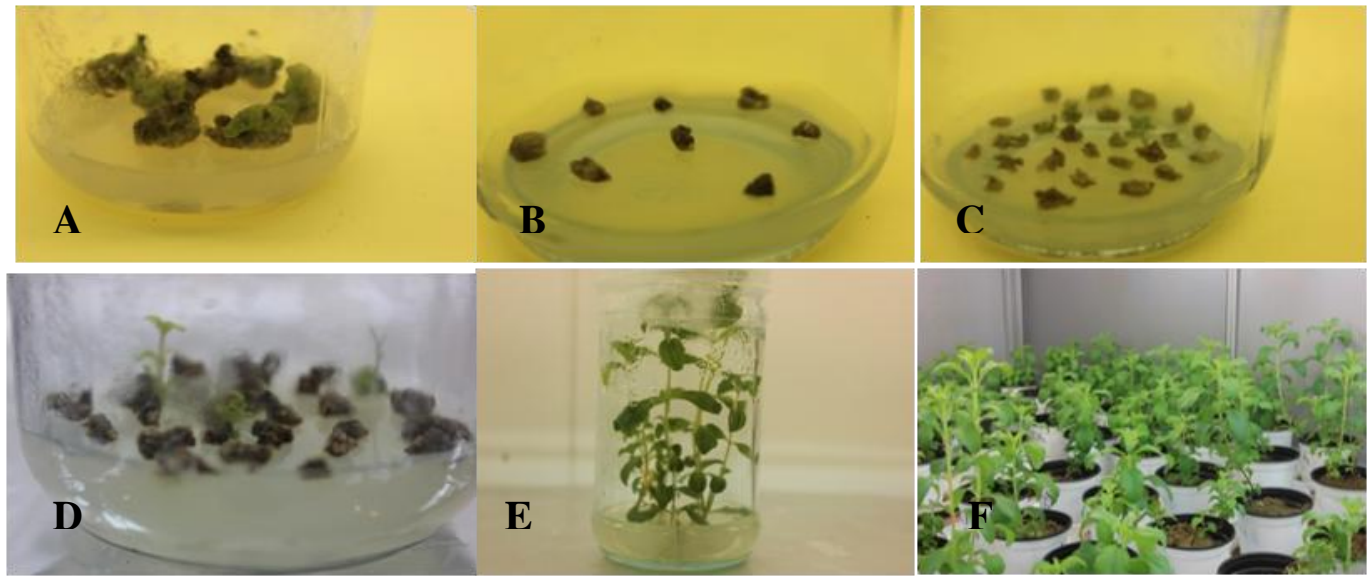

Figure 1. Different steps of stevia rebaudiana regeneration from EMS treated explants: A. Calli induced from leaf explants, B. No regeneration from calli treated with $0.2 \%$ EMS for 120 minutes. $C$. Shoot regeneration from calli treated with $0.1 \%$ EMS for 30 minutes. D. Elongation of shoots regenerated from calli treated with $0.2 \%$ EMS for 30 minutes. E. in vitro root induction, F. Acclimized plantlets

\section{Ethyl methane sulfonate (EMS) application}

A one percent stock solution of EMS was prepared and was used for preparing working EMS solutions at 0.1, 0.2, and 0.3\% final concentrations (hereafter called $\mathrm{E}_{1}$, $\mathrm{E}_{2}$, and $\mathrm{E}_{3}$, respectively). Before being used, the EMS solutions were sterilized by passing through $0.2 \mu \mathrm{m}$ filters. The calli cultured on MS medium free of growth regulators for one week, were immersed in the EMS solutions with the abovementioned concentrations for 30,60, and 120 minutes (hereafter called $T_{1}, T_{2}$, and $T_{3}$, respectively) that were incubated on rotary shaker at the constant rate of $150 \mathrm{rpm}$ at room temperature. Finally, the treated callus samples were washed three times with sterile distilled water, dried on sterile filter paper, cultured on MS medium free of growth regulators, and kept at the same temperature and photoperiod mentioned above for regeneration. The shoots regenerated from the calli in the control samples, and from calli in the EMS treatments, were cultured on MS media containing IBA at $0.2 \mathrm{mg} / \mathrm{l}$ for root formation (Figure 1). Nodal explants from regenerated plantlets were subcultured on hormone free-MS media to propagate the seedlings.

The factorial experiment on mutation induction using EMS was conducted using the completely randomized design. The factors included the treatments in which the EMS 
was applied at various concentrations and every treatment had three replications each with seven explants.

\section{The second experiment: morphological and physiological evaluations}

At this stage, each plant regenerated from calli treated with EMS was considered a mutational event, and a cloned population with similar age was prepared for each unique plant. In each treatment, the regenerated plants with suitable growth forms were selected, and each individual seedling regenerated from callus was given a unique code. The plants regenerated from control calli were also studied simultaneously. From each unique code, a clone was prepared by culturing nodes in successive cultures. After the adaptation stage, the seedlings belonging to each clone were evaluated with respect to their morphological and physiological characteristics.

\section{Acclimization}

After the seedlings grew under in vitro conditions, their roots were washed with distilled water and then were put into transparent plastic containers with lids that contained peat moss and perlite (in the ratio of 1 to 1) to preserve the moisture of the seedlings. Culture containers were kept at $25^{\circ} \mathrm{C}$ under a $16: 8 \mathrm{~h}$ light-dark photoperiod (light was provided by white fluorescent lamps) and were irrigated once a week. Two weeks after the plants were established under adaptation conditions, Hoagland's solution was used to fertilize them (Figure 1).

This experiment was conducted using as a completely randomized design with three replications. The data was analyzed by SAS, and comparison of the means was performed based on Duncan's multiple range tests at the difference level of $1 \%$ by employing MSTAT-C.

\section{Measurements of morphological traits}

Some morphological traits (fresh and dry weights of shoot, plant height, leaf surface area, stem diameter) of the plants regenerated from the control and treated calli were studied. Plants of similar age were harvested for this purpose and their heights, stem diameters, and fresh and dry weights of their shoot were measured. The shoots were placed in an oven at $70^{\circ} \mathrm{C}$ for 48 hours to measure their dry weights. Leaf surface area was measured using the Digimizer software.

\section{Chlorophyll and carotenoids measuerment}

Completely developed leaves were used to measure chlorophyll contents using the Arnon method (Arnon., 1949). Following relations was used to determine the concentrations of chlorophyll $\mathrm{a}$ and $\mathrm{b}$, chlorophyll $\mathrm{a}+\mathrm{b}$, and anthocyanins:

$$
\begin{gathered}
\text { Chlorophyll a }(\mathrm{mg} / \mathrm{g})=\{12.7(\mathrm{~A} 663)-2.69(\mathrm{~A} 645)\} * \mathrm{~V} / \mathrm{W} * 1000 \\
\text { Chlorophyll b }(\mathrm{mg} / \mathrm{g})=\left\{22.9\left(\mathrm{~A}_{645}\right)-4.68\left(\mathrm{~A}_{663}\right)\right\} * \mathrm{~V} / \mathrm{W} * 1000 \\
\text { Total chlorophyll }(\mathrm{mg} / \mathrm{g})=\left\{20.2\left(\mathrm{~A}_{645}\right)+8.02\left(\mathrm{~A}_{663}\right)\right\} * \mathrm{~V} / \mathrm{W} * 1000 \\
\text { Carotenoid } \left.=\left\{\left(1000 * \mathrm{~A}_{480}\right)-1.82 \mathrm{chl} \mathrm{a}-85.02 \mathrm{chl} \mathrm{b} / 198\right)\right\} * \mathrm{~V} / \mathrm{W} * 1000
\end{gathered}
$$


In the above relations, $\mathrm{V}$ is the total volume of the extracted sample, $\mathrm{W}$ the fresh weight, and $\mathrm{A}$ is light absorption by the extract.

A SPAD chlorophyll meter (SPAD-502 Minolta, Japan) was employed to determine the relative content of leaf chlorophyll, which was measured at four points on the leaf, and the final value was used in the calculations.

\section{Total anthocyanins}

The anthocyanin content for each extract was calculated using the following equation (Mita et al.,1997):

$$
\mathrm{A}=\mathrm{A}_{0530}-\left(0.25^{*} \mathrm{~A}_{657}\right)
$$

In the above equation, $\mathrm{A}$ is light absorption (the subscripts and superscripts represent wavelengths at which light absorption was read).

\section{Results}

Results of the ANOVA showed that EMS concentration and of exposure duration had a significant effect $(P<0.01)$ on some traits of the plants regenerated from treated calli (Table 1). Regeneration frequency, number of regenerated shoots, and times required for shoot regeneration from the calli were influenced $(P<0.01)$ by the various EMS concentrations $(0.1,0.2$ and $0.5 \%)$ and by the different exposure durations $(30,60$, and 120 minutes). All calli that were exposed to the various EMS concentrations for 120 minutes turned dark and necrosed, indicating that regeneration frequency from calli treated with EMS was strongly affected by the durations of exposure to EMS (Figure 1).

Table 1. ANOVA of the effects of EMS concentration and of exposure duration on some traits of the regenerated calli.

\begin{tabular}{ccccc}
\hline $\begin{array}{l}\text { Source of } \\
\text { Variation }\end{array}$ & $\begin{array}{l}\text { Degree of } \\
\text { freedom }\end{array}$ & $\begin{array}{c}\text { Regeneration } \\
(\%)\end{array}$ & $\begin{array}{c}\text { Shoot } \\
(\text { No. })\end{array}$ & Day \\
\hline Concentration(C) & 2 & $40.99^{* *}$ & $5.47^{* *}$ & $6.51^{* *}$ \\
Time (T) & 1 & $47.72^{* *}$ & $3.44^{* *}$ & $71.93^{* *}$ \\
$\mathrm{C} \times \mathrm{T}$ & 2 & $4.43^{* *}$ & $0.61^{* *}$ & $24.63^{* *}$ \\
Error & 14 & 0.49 & 0.08 & 0.04 \\
$\mathrm{CV}(\%)$ & & 15.14 & 14.07 & 4.62 \\
\hline
\end{tabular}

** Significant at the $1 \%$ levels of probability.

Therefore, treatments with various concentrations of EMS $(0.1,0.2$, and $0.5 \%)$ at the exposure durations of 30 and 60 minutes were used to analyze the data. The highest regeneration frequency was observed in the control. In the treatment with $0.1 \%$ EMS, regeneration frequency increased with increases in exposure duration so that the maximum percentage of regeneration was that of the 30-minute exposure duration, and 
that of 120 minutes prevented regeneration. In the treatments with EMS at 0.2 and $0.5 \%$, only the 30 -minute exposure duration led to shoot regeneration, and increasing exposure duration to 60 and 120 minutes resulted in the deterioration of the calli. Similar to regeneration frequency, the second highest number of shoots was observed in treatment with $0.1 \%$ EMS and duration exposure of 30 minutes, while the lowest number of produced shoots to the treatment with $0.5 \%$ and exposure time of 30 minutes. These results indicated the number of regenerated shoots was strongly influenced by treatment with EMS so that increases in EMS concentration and in duration exposure directly affected (and reduced) the number of produced shoots. There were no significant differences between the treatment with EMS at $0.1 \%$ and exposure duration time of 60 minutes and that with EMS at $0.2 \%$ and exposure duration of 30 minutes with respect to the number of regenerated shoots. Furthermore, various EMS concentrations influenced the time required for the emergence of shoots from calli, and increases in EMS concentration and in exposure duration increased this time. The minimum required time for shoot emergence was observed in the treatment with $0.1 \%$ EMS for 30 minutes, and the maximum to the treatment with $0.5 \%$ EMS for 120 minutes (Table 2).

Table 2. Means Comparison of the some traits related to regeneration from calli treated with EMS.

\begin{tabular}{ccccc}
\hline \multicolumn{2}{c}{ Treatment } & Regeneration & Shoot & Day \\
Concentration & Time & $(\%)$ & $(\mathrm{No})$ & $(\mathrm{No})$ \\
\hline E0 & T0 & $90.00^{\mathrm{a}}$ & $18 \mathrm{a}$ & $16 \mathrm{ab}$ \\
E1 & $\mathrm{T} 1$ & $66.67^{\mathrm{a}}$ & $9 \mathrm{ab}$ & $30.33 \mathrm{ab}$ \\
E1 & $\mathrm{T} 2$ & $26.67^{\mathrm{abc}}$ & $6 \mathrm{bc}$ & $36.67 \mathrm{ab}$ \\
E2 & $\mathrm{T} 1$ & $33.33 \mathrm{ab}$ & $5 \mathrm{bc}$ & $44 \mathrm{a}$ \\
E2 & $\mathrm{T} 2$ & $0.00 \mathrm{c}$ & $0 \mathrm{~d}$ & $0 \mathrm{~b}$ \\
E3 & $\mathrm{T} 1$ & $6.67 \mathrm{bc}$ & $1 \mathrm{~cd}$ & $55.67 \mathrm{a}$ \\
E3 & $\mathrm{T} 2$ & $0 \mathrm{c}$ & $0 \mathrm{~d}$ & $0 \mathrm{~b}$ \\
\hline
\end{tabular}

Means in each column followed by at least one letter in common are not significantly different at the $1 \%$ level of probability.

High EMS concentrations may be lethal for some explants. Our results indicated that the number of regenerated shoots was strongly influenced by treatment with EMS so that increases in EMS concentration and in duration exposure directly affected (and reduced) the number of produced shoots. So, all calli that were exposed to the various EMS concentrations for 120 minutes turned dark and necrosed. Furthermore, in our study, various EMS concentrations affected the time required for shoots to emerge from the calli so that this time increased with increases in EMS concentration and in exposure durations. The maximum regeneration was that of the 30 minute exposure time, while regeneration was prevented at the exposure duration of 120 minutes. 


\section{The second experiment}

Results of ANOVA showed that EMS had significant effects on all the studied morphological traits (fresh and dry weights of shoot, plant height, leaf surface area, and stem diameter) at the $1 \%$ level (Table 3).

Table 3. ANOVA of the some morphological traits in seedlings regenerated from EMS treated calli

\begin{tabular}{|c|c|c|c|c|c|c|c|c|}
\hline $\begin{array}{l}\text { Source of } \\
\text { Variations }\end{array}$ & $\begin{array}{c}\text { Degree } \\
\text { of } \\
\text { freedom }\end{array}$ & $\begin{array}{c}\text { Shoot } \\
\text { fresh } \\
\text { weight (gr) }\end{array}$ & $\begin{array}{c}\text { Shoot dry } \\
\text { weight } \\
\text { (gr) }\end{array}$ & $\begin{array}{l}\text { Root fresh } \\
\text { weight } \\
\text { (gr) }\end{array}$ & $\begin{array}{c}\text { Root dry } \\
\text { weight } \\
\text { (gr) }\end{array}$ & $\begin{array}{l}\text { Height } \\
(\mathrm{cm})\end{array}$ & $\begin{array}{l}\text { Leaf area } \\
\left(\mathrm{cm}^{2}\right)\end{array}$ & $\begin{array}{c}\text { Stem } \\
\text { diameter } \\
(\mathrm{mm})\end{array}$ \\
\hline Treatment & 18 & $12.92 * *$ & $3.071^{*}$ & $2.93 * *$ & $0.645 * *$ & $31.84 *$ & $5566.44 * *$ & $0.227 * *$ \\
\hline Error & 38 & 0.195 & 0.003 & 0.008 & 0.0018 & 1.701 & 34.81 & 0.029 \\
\hline C.V (\%) & & 6.62 & 2.65 & 3.24 & 5.62 & 6.20 & 3.04 & 8.843 \\
\hline
\end{tabular}

*, ** Significant at the $5 \%$ and $1 \%$ levels of probability respectively.

In eight studied mutants fresh weights of shoot were higher as compared to the control. In the mutants $\mathrm{M}_{19}, \mathrm{M}_{5}$, and $\mathrm{M}_{10}$, fresh weights of shoot were 34.1, 30.2, and $25.2 \%$ higher than the control, while the mutant $\mathrm{M}_{16}$ exhibited a $61.7 \%$ reduction in fresh weight of shoot compared to the control. In terms of dry weights of shoot $\mathbf{M}_{10}$, $\mathrm{M}_{19}$, and $\mathrm{M}_{17}$ by $+102,+97.8$, and $+87.5 \%$, respectively, showed the maximum amounts as compared to the control. Fresh weights of roots in $\mathrm{M}_{10}$ and $\mathrm{M}_{6}$ were 4.68 and 4.32 grams, respectively, which were the highest compared to that of the control (3.60 grams), while $\mathrm{M}_{16}, \mathrm{M}_{2}, \mathrm{M}_{13}$, and $\mathrm{M}_{3}$, with $1.26,1.60$, and 1.71 grams, respectively, had the minimum root fresh weights (Table 4). Comparison of the means of root dry weights indicated only 4 of the studied mutants had more dry weights than that of the control (which was 1.23 grams), while $\mathrm{M}_{6}$ and $\mathrm{M}_{16}$ with 1.43 and 0.19 grams had the maximum and minimum root dry weights, respectively (Table 4).

Table 4. Means Comparison of the some morphological traits in seedlings regenerated from EMS treated calli

\begin{tabular}{cccccccccc}
\hline Treatment & Code & $\begin{array}{c}\text { Shoot } \\
\text { fresh } \\
\text { weight } \\
\text { (gr) }\end{array}$ & $\begin{array}{c}\text { Change } \\
(\%)\end{array}$ & $\begin{array}{c}\text { Shoot } \\
\text { dry } \\
\text { weight } \\
(\mathrm{gr})\end{array}$ & $\begin{array}{c}\text { Change } \\
(\%)\end{array}$ & $\begin{array}{c}\text { Root } \\
\text { fresh } \\
\text { weight } \\
(\mathrm{gr})\end{array}$ & $\begin{array}{c}\text { Change } \\
(\%)\end{array}$ & $\begin{array}{c}\text { Root } \\
\text { dry } \\
\text { weight } \\
(\mathrm{gr})\end{array}$ & $\begin{array}{c}\text { Change } \\
(\%)\end{array}$ \\
\hline E0T0 & M1 & $7.21^{\mathrm{d}}$ & - & $1.85^{\mathrm{g}}$ & - & $3.60^{\mathrm{d}}$ & & $1.23^{\mathrm{c}}$ & - \\
E1T1 & M2 & $3.95^{\mathrm{fg}}$ & -45.2 & $1.24^{\mathrm{j}}$ & -32.9 & $1.60^{\mathrm{k}}$ & -55.5 & $0.25^{\mathrm{hi}}$ & -79.67 \\
E1T1 & M3 & $4.26^{\mathrm{f}}$ & -40.9 & $1.01^{\mathrm{k}}$ & -45.4 & $1.74^{\mathrm{k}}$ & -51.6 & $0.25^{\mathrm{hi}}$ & -79.67 \\
E1T1 & M4 & $6.90^{\mathrm{d}}$ & -4.29 & $1.67^{\mathrm{h}}$ & -9.72 & $3.84^{\mathrm{cd}}$ & +6.66 & $1.05^{\mathrm{d}}$ & -14.63 \\
E1T1 & M5 & $9.39^{\mathrm{a}}$ & +30.2 & $2.39^{\mathrm{e}}$ & +29.1 & $3.94^{\mathrm{c}}$ & +9.44 & $1.22^{\mathrm{c}}$ & -0.81
\end{tabular}




\begin{tabular}{lccccccccc} 
E1T1 & M6 & $8.17^{\mathrm{c}}$ & +13.3 & $2.69^{\mathrm{d}}$ & +45.4 & $4.32^{\mathrm{b}}$ & +20 & $1.43^{\mathrm{a}}$ & +16.26 \\
E1T1 & M7 & $5.21^{\mathrm{e}}$ & -27.7 & $1.06^{\mathrm{k}}$ & -42.7 & $2.28^{\mathrm{i}}$ & -36.6 & $0.23^{\mathrm{hi}}$ & -81.30 \\
E1T1 & M8 & $6.85^{\mathrm{d}}$ & -4.99 & $2.03^{\mathrm{f}}$ & +9.72 & $2.63^{\mathrm{fg}}$ & -26.9 & $0.61^{\mathrm{f}}$ & -50.41 \\
E1T1 & M9 & $3.43^{\mathrm{gh}}$ & -52.4 & $0.53^{1}$ & -71.3 & $2.49^{\mathrm{gh}}$ & -30.8 & $0.62^{\mathrm{f}}$ & -49.59 \\
E1T2 & M10 & $9.03^{\mathrm{ab}}$ & +25.2 & $3.74^{\mathrm{a}}$ & +102 & $4.68^{\mathrm{a}}$ & +30 & $1.39^{\mathrm{ab}}$ & +13.01 \\
E1T2 & M11 & $8.35^{\mathrm{bc}}$ & +15.8 & $3.14^{\mathrm{c}}$ & +69.7 & $3.49^{\mathrm{d}}$ & -3.05 & $1.36^{\mathrm{b}}$ & +10.57 \\
E1T2 & M12 & $6.81^{\mathrm{d}}$ & -5.54 & $2.35^{\mathrm{e}}$ & +27 & $3.51^{\mathrm{d}}$ & -2.5 & $0.66^{\mathrm{f}}$ & -46.34 \\
E1T2 & M13 & $7.32^{\mathrm{d}}$ & +1.52 & $2.64^{\mathrm{d}}$ & +42.7 & $1.71^{\mathrm{k}}$ & -52.5 & $0.27^{\mathrm{gh}}$ & -78.05 \\
E1T2 & M14 & $6.81^{\mathrm{d}}$ & -5.54 & $1.55^{\mathrm{i}}$ & -16.2 & $2.10^{\mathrm{j}}$ & -41.6 & $0.30^{\mathrm{gh}}$ & -75.61 \\
E1T2 & M15 & $4.52^{\mathrm{ef}}$ & -37.3 & $1.19^{\mathrm{j}}$ & -35.6 & $2.08^{\mathrm{j}}$ & -42.2 & $0.32^{\mathrm{g}}$ & -73.98 \\
E2T1 & M16 & $2.76^{\mathrm{h}}$ & -61.7 & $0.56^{\mathrm{i}}$ & -69.7 & $1.26^{\mathrm{i}}$ & -65 & $0.19^{\mathrm{i}}$ & -84.55 \\
E2T1 & M17 & $8.10^{\mathrm{c}}$ & +12.3 & $3.47^{\mathrm{b}}$ & +87.5 & $2.77^{\mathrm{f}}$ & -23 & $0.88^{\mathrm{e}}$ & -28.46 \\
E2T1 & M18 & $8.06^{\mathrm{c}}$ & +11.7 & $2.71^{\mathrm{d}}$ & +46.4 & $2.44^{\mathrm{h}}$ & -32.2 & $0.84^{\mathrm{e}}$ & -31.71 \\
E3T1 & M19 & $9.67^{\mathrm{a}}$ & +34.1 & $3.66^{\mathrm{b}}$ & +97.8 & $3.18^{\mathrm{e}}$ & -11.6 & $1.32^{\mathrm{b}}$ & +7.32 \\
\hline
\end{tabular}

Means in each column followed by at least one letter in common are not significantly different at the $1 \%$ level of probability.

Considering plant height, seven mutants were taller than the control, among which $\mathrm{M}_{17}, \mathrm{M}_{18}$, and $\mathrm{M}_{13}$ were the tallest. Moreover, the shortest plants belonged to $\mathbf{M}_{9}$. Comparison of the means showed that only four of the studied mutants head higher leaf surface areas compared to the control. The minimum leaf surface area $\left(130.5 \mathrm{~cm}^{2}\right)$ was that of $\mathrm{M}_{9}$, while $\mathrm{M}_{12}, \mathrm{M}_{11}, \mathrm{M}_{8}$, and $\mathrm{M}_{6}$ with 294.2, 245.7, 240, and $235 \mathrm{~cm}^{2}$ had the maximum leaf surface areas compared to the control (the leaf surface area of which was $153.9 \mathrm{~cm}^{2}$ ).

Comparison of the means of stem diameters revealed that $\mathrm{M}_{3}$ with $2.47 \mathrm{~mm}$ had the maximum stem diameter (which was $55.35 \%$ higher than that of the control) (Table 5).

Table 5. Means Comparison of the some morphological traits in seedlings regenerated from EMS treated calli

\begin{tabular}{cccccccc}
\hline Treatment & Code & $\begin{array}{c}\text { Height } \\
(\mathrm{cm})\end{array}$ & $\begin{array}{c}\text { Change } \\
(\%)\end{array}$ & $\begin{array}{c}\text { Leaf } \\
\text { area } \\
\left(\mathrm{cm}^{3}\right)\end{array}$ & $\begin{array}{c}\text { Change } \\
(\%)\end{array}$ & $\begin{array}{c}\text { Stem } \\
\text { diameter } \\
(\mathrm{mm})\end{array}$ & $\begin{array}{c}\text { Change } \\
(\%)\end{array}$ \\
\hline E0T0 & - & $22.3 \mathrm{de}$ & - & $153.9 \mathrm{~h}$ & - & $1.59 \mathrm{~g}$ & - \\
E1T1 & M2 & $23.6 \mathrm{bcd}$ & +5.96 & $141.7 \mathrm{i}$ & -7.93 & $2.27 \mathrm{ab}$ & +42.77 \\
E1T1 & M3 & $20 \mathrm{fg}$ & -10.43 & $171.7 \mathrm{~g}$ & +11.5 & $2.47 \mathrm{a}$ & +55.35 \\
E1T1 & M4 & $23 \mathrm{cde}$ & +3.00 & $175 \mathrm{~g}$ & +13.7 & $2.43 \mathrm{a}$ & +52.83 \\
E1T1 & M5 & $21.3 \mathrm{ef}$ & -4.48 & $224.6 \mathrm{~d}$ & +45.9 & $2.07 \mathrm{bcd}$ & +30.19 \\
\hline
\end{tabular}




\begin{tabular}{llcccccc}
\hline E1T1 & M6 & $17.3 \mathrm{~h}$ & -22.39 & $235 \mathrm{c}$ & +52.7 & $1.69 \mathrm{fg}$ & +6.29 \\
E1T1 & M7 & $19.6 \mathrm{fg}$ & -11.96 & $181.2 \mathrm{fg}$ & +17.7 & $2.14 \mathrm{bc}$ & +34.59 \\
E1T1 & M8 & $18 \mathrm{gh}$ & -19.39 & $240 \mathrm{bc}$ & +55.9 & $1.71 \mathrm{efg}$ & +7.55 \\
E1T1 & M9 & $14.6 \mathrm{i}$ & -34.35 & $130.5 \mathrm{j}$ & -15.2 & $1.76 \mathrm{efg}$ & +10.69 \\
E1T2 & M10 & $22.6 \mathrm{cde}$ & +1.48 & $220.8 \mathrm{~d}$ & +43.4 & $2.28 \mathrm{ab}$ & +43.40 \\
E1T2 & M11 & $22.6 \mathrm{cde}$ & +1.48 & $245.7 \mathrm{~b}$ & +59.6 & $1.73 \mathrm{efg}$ & +8.81 \\
E1T2 & M12 & $21.6 \mathrm{def}$ & -3.00 & $294.2 \mathrm{a}$ & +91.1 & $1.97 \mathrm{cde}$ & +23.90 \\
E1T2 & M13 & $25.3 \mathrm{ab}$ & +13.43 & $139 \mathrm{ij}$ & -9.68 & $1.97 \mathrm{cde}$ & +23.90 \\
E1T2 & M14 & $21.6 \mathrm{def}$ & -3.00 & $145.9 \mathrm{hi}$ & -5.20 & $1.67 \mathrm{fg}$ & +5.03 \\
E1T2 & M15 & $17.3 \mathrm{~h}$ & -22.39 & $204.9 \mathrm{e}$ & +33.1 & $1.78 \mathrm{efg}$ & +11.95 \\
E2T1 & M16 & $16.6 \mathrm{hi}$ & -25.39 & $185 \mathrm{f}$ & +20.2 & $1.59 \mathrm{~g}$ & 0 \\
E2T1 & M17 & $27.3 \mathrm{a}$ & +22.39 & $189.6 \mathrm{f}$ & +23.2 & $1.94 \mathrm{cdef}$ & +22.01 \\
E2T1 & M18 & $24.6 \mathrm{bc}$ & +10.43 & $188.3 \mathrm{f}$ & +22.3 & $1.88 \mathrm{cdef}$ & +18.24 \\
E3T1 & M19 & $19.6 \mathrm{fg}$ & -11.96 & $208 \mathrm{e}$ & +35.5 & $1.80 \mathrm{dgef}$ & +13.21 \\
\hline
\end{tabular}

Means in each column, followed by similar letter are not significantly different at the $1 \%$ level of probability

Results of ANOVA revealed that EMS application had significant effects on the contents of chlorophyll a and b, carotenoids, and anthocyanins at the $1 \%$ level (Table 6 ).

Table 6. ANOVA of the some physiological traits in seedlings regenerated from EMS treated calli

\begin{tabular}{ccccccc}
\hline S.O.V & Df & Chl a & Chl b & Total Chl & Car & Antho \\
\hline Tretment & 18 & $0.1609^{* *}$ & $0.1748^{* *}$ & $0.622^{* *}$ & $0.035^{* *}$ & $0.014^{* *}$ \\
Error & 38 & 0.00008 & 0.00021 & 0.0001 & 0.00004 & 0.00003 \\
C.V & & 2.297 & 3.203 & 1.484 & 4.55 & 3.49 \\
\hline
\end{tabular}

**Significant at the $1 \%$ levels of probability

The results showed $\mathrm{M}_{10}$ had a higher chlorophyll a content compared to the control, and $\mathrm{M}_{11}, \mathrm{M}_{17}$, and $\mathrm{M}_{19}$ with $0.724,0.670$ and $0.589 \mathrm{mg} / \mathrm{g}$, respectively, had the maximum chlorophyll a contents compared to the control (which was $0.193 \mathrm{mg} / \mathrm{g}$ ). Furthermore, $\mathrm{M}_{9}$ and $\mathrm{M}_{2}$ with 0.109 and $0.117 \mathrm{mg} / \mathrm{g}$, respectively, had the minimum chlorophyll a contents (Table 7). Moreover, 13 of the studied mutants had higher contents of chlorophyll b compared to the control, with the chlorophyll contents in $\mathrm{M}_{11}$, $\mathrm{M}_{19}, \mathrm{M}_{6}$, and $\mathrm{M}_{17}$ being 270, 270, 206, and 188\% greater, respectively, compared to the control, while that of $\mathrm{M}_{9}$ was $26.6 \%$ lower compared to the control. In addition, 13 mutants had higher total chlorophyll contents as compared to the control, with $\mathbf{M}_{11}, \mathbf{M}_{10}$, and $\mathrm{M}_{6}$ having the maximum total chlorophyll contents (Table 7). 
Table 7. Means Comparison of the some physiological traits in the regenerated seedling of calluses expsured at EMS

\begin{tabular}{|c|c|c|c|c|c|c|c|c|c|c|c|}
\hline Treatment & Code & $\begin{array}{l}\text { Chl a } \\
(\mathrm{mg} / \mathrm{g})\end{array}$ & $\begin{array}{c}\text { Change } \\
(\%)\end{array}$ & $\begin{array}{l}\text { Chl b } \\
(\mathrm{mg} / \mathrm{g})\end{array}$ & $\begin{array}{c}\text { Change } \\
(\%)\end{array}$ & $\begin{array}{c}\text { Total } \\
\mathrm{Chl}(\mathrm{mg} / \mathrm{g})\end{array}$ & $\begin{array}{c}\text { Change } \\
(\%)\end{array}$ & $\begin{array}{c}\mathrm{Car} \\
(\mathrm{mg} / \mathrm{g})\end{array}$ & $\begin{array}{c}\text { Change } \\
(\%)\end{array}$ & $\begin{array}{c}\text { Anthocyanin } \\
(\mu \mathrm{mol} / \mathrm{g})\end{array}$ & $\begin{array}{c}\text { Change } \\
(\%)\end{array}$ \\
\hline E0T0 & - & $0.193^{\mathrm{m}}$ & - & $0.240^{\mathrm{kj}}$ & - & $0.41^{1 \mathrm{Im}}$ & - & 0.051 & - & $0.067^{\mathrm{m}}$ & - \\
\hline E1T1 & M2 & $0.117^{\text {no }}$ & -39.38 & $0.201^{\mathrm{Im}}$ & -16.2 & $0.308^{n}$ & -26.1 & $0.0112^{\mathrm{n}}$ & -78 & $0.181^{\mathrm{e}}$ & +170.15 \\
\hline E1T1 & M3 & $0.273^{\mathrm{i}}$ & +41.45 & $0.436^{\mathrm{h}}$ & +81.6 & $0.617^{\mathrm{j}}$ & +47.9 & $0.030^{\mathrm{m}}$ & -40 & $0.087^{1}$ & +29.85 \\
\hline E1T1 & M4 & $0.315 \mathrm{~h}$ & +63.21 & $0.503^{\mathrm{fg}}$ & +109 & $0.811^{\mathrm{i}}$ & +94.4 & $0.168^{\mathrm{f}}$ & +236 & $0.192 \mathrm{~d}$ & +186.57 \\
\hline E1T1 & M5 & $0.512^{\mathrm{e}}$ & +165.2 & $0.643^{\mathrm{d}}$ & +167 & $1.14^{\mathrm{f}}$ & +173 & $0.263^{\mathrm{c}}$ & +426 & $0.268^{b}$ & +300 \\
\hline E1T1 & M6 & $0.679^{\mathrm{c}}$ & +251.8 & $0.736^{\mathrm{b}}$ & +206 & $1.35^{\mathrm{d}}$ & +223 & $0.355^{\mathrm{b}}$ & +610 & $0.136^{\mathrm{h}}$ & +102.99 \\
\hline E1T1 & M7 & $0.514^{\mathrm{e}}$ & +166.3 & $0.479^{g}$ & +99.5 & $0.98^{g}$ & +135 & $0.094^{\mathrm{j}}$ & +88 & $0.112^{\mathrm{jk}}$ & +67.16 \\
\hline E1T1 & M8 & $0.227^{\mathrm{k}}$ & +17.62 & $0.216^{\mathrm{kl}}$ & -10 & $0.428^{1}$ & +2.64 & $0.234^{\mathrm{d}}$ & +368 & $0.111^{\mathrm{jk}}$ & +65.67 \\
\hline E1T1 & M9 & $0.109^{\circ}$ & -43.52 & $0.176^{\mathrm{n}}$ & -26.6 & $0.277^{\circ}$ & -33.5 & $0.051^{1}$ & +2 & $0.126^{\mathrm{i}}$ & +88.06 \\
\hline $\mathrm{E} 1 \mathrm{~T} 2$ & M10 & $0.885^{\mathrm{a}}$ & +358.5 & $0.637^{\mathrm{d}}$ & +165 & $1.50^{\mathrm{b}}$ & +259 & $0.379^{\mathrm{a}}$ & +658 & $0.156^{\mathrm{g}}$ & +132.84 \\
\hline $\mathrm{E} 1 \mathrm{~T} 2$ & M11 & $0.724^{\mathrm{b}}$ & +275.1 & $0.890^{\mathrm{a}}$ & +270 & $1.58^{\mathrm{a}}$ & +278 & $0.105^{\mathrm{i}}$ & +110 & $0.118^{\mathrm{ij}}$ & +76.12 \\
\hline E1T2 & M12 & $0.257^{\mathrm{j}}$ & +33.1 & $0.251^{\mathrm{j}}$ & +4.58 & $0.499^{\mathrm{k}}$ & -19.6 & $0.025^{\mathrm{m}}$ & -50 & $0.193^{d}$ & +188.06 \\
\hline E1T2 & M13 & $0.386^{\mathrm{g}}$ & +100 & $0.527^{\mathrm{f}}$ & +119 & $0.89^{h}$ & +113 & $0.182^{\mathrm{e}}$ & +264 & $0.317^{\mathrm{a}}$ & +373.13 \\
\hline $\mathrm{E} 1 \mathrm{~T} 2$ & M14 & $0.209^{1}$ & +8.29 & $0.221^{\mathrm{kl}}$ & -7.92 & $0.40^{\mathrm{m}}$ & -4.08 & $0.033^{\mathrm{m}}$ & -34 & $0.251^{\mathrm{c}}$ & +274.63 \\
\hline $\mathrm{E} 1 \mathrm{~T} 2$ & M15 & $0.128^{n}$ & -33.68 & $0.18^{\mathrm{mn}}$ & -25 & $0.29^{\text {no }}$ & -30.4 & $0.131^{\mathrm{h}}$ & +162 & $0.138^{h}$ & +105.97 \\
\hline E2T1 & M16 & $0.276^{\mathrm{i}}$ & +43.01 & $0.288^{\mathrm{i}}$ & +20 & $0.51^{\mathrm{k}}$ & +22.3 & $0.071^{\mathrm{k}}$ & +42 & $0.264^{b}$ & +294.03 \\
\hline E2T1 & M17 & $0.670^{c}$ & +247.1 & $0.692^{\mathrm{c}}$ & +188 & $1.33^{\mathrm{e}}$ & +218 & $0.191^{\mathrm{e}}$ & +282 & $0.171^{\mathrm{f}}$ & +155.2 \\
\hline E2T1 & M18 & $0.472^{\mathrm{f}}$ & +144.5 & $0.576^{\mathrm{e}}$ & +140 & $0.99^{\mathrm{g}}$ & +137.4 & $0.152^{\mathrm{g}}$ & +204 & $0.107^{k}$ & +59.70 \\
\hline E3T1 & M19 & $0.589^{d}$ & +205.1 & $0.889^{\mathrm{a}}$ & +270 & $1.46^{\mathrm{c}}$ & +250 & $0.152^{g}$ & +204 & $0.106^{\mathrm{k}}$ & +58.21 \\
\hline
\end{tabular}

Means in each column, followed by similar letter are not significantly different at the $1 \%$ level of probability 
Moreover, $\mathrm{M}_{10}, \mathrm{M}_{6}, \mathrm{M}_{5}$ had the highest contents of carotenoids $(0.379,0.355$, and 0.263 $\mathrm{mg} / \mathrm{g}$, respectively as compared to the control $(0.050 \mathrm{mg} / \mathrm{g})$, while $\mathrm{M}_{2}$ with $0.011 \mathrm{mg} / \mathrm{g}$ had the lowest total chlorophyll content. All the studied mutants had greater anthocyanin contents as compared to the control (Table 7).

\section{Discussion}

Mutagenesis is an efficient tool to extend variability and to isolate desirable economic traits in a shorter period compared with conventional breeding procedures. With the discovery of mutagenic agents, both physical and chemical, plant breeders have the ability to induce variability and use it in their breeding programmes. Characters of interest can only be improved through mutation breeding if the population shows low variability for a given characteristics (Yadav et al., 2011). Mutation induction under in vitro conditions can substantially increase penetration of the mutagen into tissues (Van Harten., 1998). In the study conducted by Zhu et al. (1995). it was found high EMS concentrations (higher than $0.9 \%$ ) reduced the desirable effects of mutations in soybean (Glycine $\max$ L.). The effects of the EMS mutagenic agent on some morphological traits of pepper (Jabeen and Mirza., 2004), cowpea (Gnanamurthy et al., 2014), bell pepper (Alcantara et al., 1996), peas (Wani et al., 2002), and tomato (Saba and Mirza., 2002) were previously reported. Results of these studied resembled those we found in our study. For example, Jabeen et al. (2004) exposed pepper seeds to EMS and showed plants grown from these seeds were taller or shorter than the controls.

Furthermore, Alcantara et al. (1996) reported that application of various concentrations of EMS increased leaf surface area and caused variegation in some the leaves in pepper plants. Wani and Anis (2002) studied the effects of EMS and Gamma rays on peas, and reported that the applied treatments improved quantitative traits such plant height, number of branches, 1000-seed weight, and yield. Research carried out by Saba and Mirza (2002) indicated all samples of tomato plants that were exposed to various EMS concentrations and different exposure durations had greater yields compared to the control. Various studies have reported the effects of EMS on wheat (Triticum aestivum L.), rice (Oryza sativa L.), cowpea (Vigna unguiculata), and petunia (Petunia hybrida Vilm). Larick et al. (1980) showed application of EMS on wheat plants (cv. 'Al-Sama') changed chlorophyll content. Kaul and Bhan (1977) exposed three rice cultivars to the mutagenic agents EMS, DES, and Gamma rays, and to combinations of them, and found chlorophyll content increased under the influence of these mutagens, with the extent of albinism being greater in the M1 generation under the influence of EMS compared to the other mutagenic agents. In another study, application of various EMS concentrations on cowpea induced mutations, and results indicated some of the mutated samples had lower chlorophyll contents while in some others abnormal leaves with yellowish albino colors were observed (Gnanamurthy and Dhanavel, 2014). A study was conducted on the effects of EMS on some growth and development features of regenerated petunia plants. Results showed the treatment with EMS at $1 \%$ and with exposure duration of 15 minutes had the maximum chlorophyll a content, chlorophyll $\mathrm{b}$ contents increased in plants treated with $1 \%$ EMS with exposure duration of 15, 30, and 60 minutes. Moreover, carotenoid content in the treatment with $1 \%$ EMS and exposure duration of 15 minutes was significantly greater compared to that of the control at the 5\% level. The induction of mutagenesis through EMS treatment in Asteracantha longifolia has also been known to affect plant height, internode length, morphology, and even leaf size (Behera et al., 2012). Also, lower 
doses of EMS and gamma treatments have been found effective in altering the physiological, genetical, and chemical state of S. rebaudiana plants, and further generation wise study of the raised variants may lead to new variety development with desirable traits (Khan et al., 2016).

\section{Conclusions}

Products like stevia sweetener will increasingly be in demand due to consumer interest in natural products. Development of new varieties of $S$. rebaudiana with a superior qualitative and quantitative features is the primary aim of plant breeders concerned with the improvement and utilization of this source of natural sweeteners.

Results of the first experiment showed that some traits of the plants regenerated from treated calli (percentage of regeneration, number of produced shoots, and the period required for regeneration of shoots from calli) were influenced by various concentrations of EMS and by the different exposure durations. It was observed the number of produced shoots decreased directly by increases in EMS concentrations and in exposure durations so that all calli exposed to various EMS concentrations for 120 minutes darkened and died. Furthermore, various EMS concentrations affected the period required for shoots to emerge from the calli so that this period increased with increases in EMS concentration and in exposure durations. The maximum regeneration was that of the 30 minute exposure time, while regeneration was prevented at the exposure duration of 120 minutes. Results of ANOVA regarding the second experiment indicated that, among the studied mutated samples, $\mathbf{M}_{10}, \mathrm{M}_{11}$, and $\mathrm{M}_{6}$ exhibited the best responses to EMS application in most of the 12 studied morphological and physiological traits, and demonstrated the greatest increases in the studied traits compared to the control.

\section{REFERENCES}

[1] Abd El. Hamid, A., Abo Shosha, M.K.M, Kassem, E.E.M. (2014): Biotechnological Studies on Gamma Irradiated Stevia (Stevia Rebaudiana) Plant Under Abiotic Stresses. Int. Conference on Radiation Sciences and Application. Taba. Egypt. 95: 109.

[2] Adamu, A.K., Aliyu, H. (2007): Morphological effects of sodium azide on tomato (Lycopersicon esculentum Mill). - Science World Journal 2(4):9-12.

[3] Alcantara, T.P., Bosland, P.W., Smith, D.W (1996): Ethyl methane sulfonate induced mutagenesis of Capsicum annuum L. - J. Hered (8): 239-241.

[4] Ali, A.A., Aboshosha, A.A., Kassem, M.K., Eman, I., EL-Banna, A.N. (2015): Salinity Tolerance and Stevioside Improvement of In vitro Selected Stevia (Stevia rebaudiana) Mutants. - Int.J.Curr.Res.Biosci.Plantbiol.2 (4): 11-20.

[5] Arnon, D.I. (1949): Copper enzymes in isolated chloroplast polyphenol oxide in betavulgaris. -Plant Physiol 24: 1-5.

[6] Behera, M., Panigrahi, J., Mishra, R.R., Rath, S.P. (2012): Analysis of EMS induced in vitro mutants of Asteracantha longifolia (L.) Nees using RAPD markers. - Indian J Biotechnol (11):39-47.

[7] Gnanamurthy, S., Dhanavel, D. (2014): Effect of EMS on induced morphological mutants and chromosomal variation in Cowpea (Vigna unguiculata L.). - Int. Lett. Nat. Sci 22: 3343.

[8] Jabeen, N., Mirza, B. (2004): Ethyl methane sulfonate enhances genetic variability in Capsicum annuum. - Int. J. Agric. Biol 6, 340-345. 
[9] Jain, S.M. (2006): Mutation-assisted breeding in ornamental plant improvement. - Acta. Hort 714: 85-98.

[10] Kaul, M.L., Bhan, A.K. (1977): Mutagenic effectiveness and efficiency of EMS, DES and gamma-ray in rice. - Theor. Appl. Genet 50(5):241-246.

[11] Khalil, S.A., Zamir, R., Ahmad, N. (2014): Effect of different propagation techniques and gama irradiation on major steviol glycoside's content in stevia rebaudiana. - J. Anim. Plant Sci 24(6): 1743-1751.

[12] Khan, S.A., Rahman, L.U., Verma, R., Shanker, K. (2016): Physical and chemical mutagenesis in Stevia rebaudiana: variant generation with higher UGT expression and glycosidic profile but with low photosynthetic capabilities. Acta Physiol Plant. 38:4

[13] Larik, A.S., Siddiqui, K.A., Soomro, A.H. (1980): Estimates of genetic variability in mutated populations of Triticum aestvum L. - Pak. J. Bot 12(1): 31-41.

[14] Mita, S., Murano, N., Akaike, M., Nakamura, K. (1997): Mutants of Arabidopsis thaliana with pleiotropic effects on the expression of the gene for beta-amylase and on the accumulation of anthocyanin that are inducible by sugars. - Plant Journal 11: 841-851.

[15] Mondaca, L., Galve, A., Bravo, L., Hen, K. (2012): Stevia rebaudiana Bertoni source of a high-potency natural Swetener: A comprehensive review on the biochemical, nutritional and functional aspects. - Food chem. 132: 1121-1132.

[16] Saba, N., Mirza, B. (2002): Ethyl Methane Sulfonate Induced Genetic Variability in Lycopersicon esculentum. - Int. J. Agric. - Biol 04-1-89-92 1560-8530.

[17] Sengupta, S., Datta, A.K. (2005): Induced narrow leaf mutant of sesame (Sesamum indicum L.). - Indian. J. Genet 65(1): 59-60.

[18] Taware, A.S., Mukadam, D.S., Chavan, A.M., Tawar, S.D. (2010): Comparative studies of in vitro and in vivo grown plants and callus of Stevia rebaudiana Bertoni. - Int. J. Integr.Biol 9(1): 10-15.

[19] Tripathi, L., and Tripathi, J.N. (2003): Role of biotechnology in medicinal plants. - Trop. J. Pharm. Res 2: 243-253.

[20] VanHarten, A.M. (1998): Mutation breeding: Theory and practical applications. Cambridge University Press, London, U.K.

[21] Wani, A.A., Anis, M. (2002): Effect of physical and chemical mutagens on some biological parameters in chickpea (Cicer arietinum L.). - SKUAST J. Res 4: 19-22.

[22] Waungh, R., Leader, D.J., Callum, M.C., Caldwell, D. (2006): Harvesting the potential of induced biological diversity Trends in Plant. - Sci .11: 71-79.

[23] Yadav, A.K., Singh, S., Dhyani, D., Ahuja, P.S. (2011): A review on the improvement of Stevia rebaudiana Bertoni. - Can. J. Plant Sci 91: 1-27.

[24] Zhu, B., Gu, A., Deng, X., Geng, Y., Lu, Z. (1995): Effects of caffeine or EDTA posttreatment on EMS mutagenesis in soybean. - Mut. Res 334: 157-159. 